\title{
An Investigation of Personality and L2 Oral Performance
}

\author{
Zhengdong Gan \\ The Hong Kong Institute of Education, Hong Kong \\ Email: zdgan@ied.edu.hk
}

\begin{abstract}
This study investigates one dimension of personality, extroversion-introversion, and examines its potential impact on learner L2 oral performance. The study is innovative in that it analyzes not only the correlation between degree of extroversion and assessment scores based on analytic scoring but also the correlation between degree of extroversion and the discourse measures of accuracy, fluency and complexity commonly used as indices of $L 2$ task performance in the $L 2$ research. The data for this study were drawn from oral performances by 39 Cantonese-mother-tongue Form 4 (that is, Grade 9) secondary school ESL students engaging in school-based oral English assessment that has recently been implemented across secondary schools in Hong Kong. The Eysenck Personality Questionnaire was used to measure the students' degree of extroversion. The findings indicate no significant correlations between degree of extroversion and students' assessment scores, and between degree of extroversion and those discourse-based measures. In addition, further in-depth analysis of the discourse and interactional behavior of two students classified as an extrovert and an introvert based on their scores on the Eysenck Personality Questionnaire, suggests that in the context of group oral discussion described in this study, extroversion/introversion might impact in some way on learner discourse and interactional behavior only in the extreme cases, yet this influence seemed not reflected in the assessment scores assigned.
\end{abstract}

Index Terms - $\mathbf{L} 2$ task performance, conversation analysis, extroversion-introversion, speaking assessment

\section{INTRODUCTION}

Group oral tasks in which three or more second language learners are required to talk to each other about a topic without any prompting from or interaction with interlocutors commonly occur in second language (L2) classrooms and L2 assessment situations. Interest in group oral tasks can be attributed to such factors as the potential to yield authentic discourse resulting from approximating real world communication (Ockey, 2009), the alignment of task-based assessment with task-based instruction, and the limitations of discrete-skills assessments (Mislevy, Steinberg, and Almond, 2002). Spence-Brown (2001) emphasizes that authenticity of engagement in interaction clearly has implications for the validity of a task for learning, as well as its validity for assessment. Bachman and Palmer (1996) also remind us that authenticity, interactiveness and impact are three qualities that many measurement specialists consider to be part of validity. Researchers and practitioners in L2 pedagogy and L2 testing and assessment thus generally agree that learner group oral task, compared with monologic narrative tasks or traditional one-to-one interviews, may more authentically reflect students' interactional skills and their moment-by-moment construction of individual and linguistic identity, and more faithfully mirror daily L2 classroom interactions.

In recent years, there have also been a few research studies on the nature of interactional discourse produced in paired or group oral tasks. Nakatsuhara (2006) investigated the impact of paired interlocutor proficiency-levels on the nature and quantity of paired testing performance. She observed a similar degree of asymmetric interactional conversational styles both in same-proficiency-level pairs and different-proficiency-level pairs. Iwashita (1996) also found that proficiency level of the paired candidates could affect the discourse produced but not the scores assigned. Viewing oral performance from what he refers to as a sociocognitive perspective, O'Sullivan (2002) examined 32 Japanese learners who were required to perform three different tasks once with a friend and once with a stranger. His findings showed that familiarity with one's partner tends to affect pair-work language performance, although his analysis did not show any effect on the linguistic complexity of the discourse produced. In light of these findings, he called for urgent and extensive study of pair/group oral work that employs tasks requiring interaction between individuals. Dimitrova-Galaczi (2004) conducted an interesting study on the interactional features observed in the First Certificate of English (FCE) speaking test. Her analysis of the discourse of the 30 dyads revealed four distinct patterns of interaction which she labeled as "collaborative," "parallel," "asymmetric", and "blended". The collaborative pattern was characterized by some dyad members working in a collaborative manner and sustaining topics over longer stretches of discourse; the parallel pattern was characterized by dyad members having equal access to the conversational floor and development of the task but not working together; the asymmetric pattern was characterized by one assuming an interactionally more dominant role and the other a more passive role; the blended pattern was characterized by some dyads exhibiting interactional features of several interactional patterns such as collaborative and parallel.

In spite of the empirical studies of discourse and interaction in oral assessment context as reviewed above, it is 
suggested that more research work needs to be carried out on learner group oral work to inform the L2 pedagogy field's understanding of the factors that may affect learner linguistic performances (Swain, 2001). In particular, Ockey (2009) mentioned that relatively much less attention has been given to effects of learner personality characteristics on learner linguistic performance in group oral task context. The present study thus aims to investigate how learner extroversion level may affect their oral performance in group oral assessment situations.

Learner personality and L2 performance

The aspect of personality that has received most attention in second language pedagogy research is extroversion and introversion, which results from personality theories developed in the field of psychology. According to Eysenck and Eysenck (1985), a highly extroverted person is sociable, easy-going, has many friends, needs excitement, and tends to be aggressive and a risk-taker, whereas a highly introverted person is quiet, reserved and introspective, and seldom behaves in an aggressive manner. A widely-held belief in the language pedagogy community is that extroverts are more likely to perform better in L2 use and communication situations. This belief is largely based on the assumption that because of extroverts' preferences for social activities, they are more willing to speak out and demonstrate a greater desire to communicate, which may enable them to achieve a higher level of speaking fluency (Swain 1993). However, to date there has been little empirical evidence that supports this hypothesis.

Relatively few studies have examined the effects of learner personality on L2 performance. Naiman, Frohlich, Stern and Todesco (1978), who examined personality characteristics and linguistic performance among a group of Canadian students learning French as a second language, found no correlation between extroversion scores and the learners' French language performance. In a comprehensive review of the literature concerning personality and linguistic performance, Dewaele and Furnham (2000) suggest that extroversion may not be a predictor of L2 learner linguistic performance. For example, Ehrman and Oxford's study (1995) revealed no effect of extroversion-introversion on end-of-training proficiency measures. Carrell, Prince and Astika (1996) found that except that the introverts performed significantly better than the extroverts on the vocabulary and composite course measures, there were no other direct relationships between personality and language performance measures. Most recently, in a study of 3145 students participating in full-time, intensive training in over 60 languages, Ehrman (2008) found the students who performed the best in speaking and reading assessment tended to be introverted personalities.

Meanwhile, there are a number of other studies that demonstrated significant relationships in some way between personality characteristics and L2 learner oral performance. Berry's (2004) investigation of extroversion and group oral performance showed that both extroverts and introverts were assigned higher scores for their performance when placed in groups with a high mean level of extroversion, and that the scores of the introverts were suppressed when placed in groups with a low mean level of extroversion. Ockey (2009) also found a complex relationship between test takers' scores on the group oral assessment and the personal characteristics of a test taker's group members. Assertive test takers' scores were affected by the assertiveness of a test taker's group members, while non-assertive test takers' scores were not found to be affected by the personal characteristics of the test taker's group members. Relying on calculating discourse-based linguistic measures of accuracy and fluency, Dewaele and Furnham (2000) analyzed the French oral interlanguage of 25 Flemish university students and related these measures to the students' extroversion scores. They found that extroverts were generally more fluent than the introverts.

In general the available research into personality characteristics and L2 performance that has so far yielded inconsistent findings largely relied on psychometric analyses of certain personality traits and analytic or overall score data drawn from subjective ratings of learner language performance. This study which views learners' oral linguistic performance as discourse constructed through interactions employed various discourse-based linguistic measures for assessing learners' oral performance, in addition to use of assessment scores awarded by the assessor. Besides correlating these linguistic measures and scores to participants' degree of extroversion measured by the Eysenck Personality Questionnaire, in-depth analysis of the discourse and interaction of an extrovert and an introvert were conducted to further examine whether and how personality characteristics might be manifested in their verbal and non-verbal behavior. The major research question addressed in this article is:

- How does learner extroversion level relate to their L2 oral performance in a group oral assessment context?

\section{THIS STUDY}

\section{A. Participants and Assessment Task}

In line with a paradigm shift in approaches to both learning and assessment, the Hong Kong Examinations and Assessment Authority (HKEAA) has recently introduced a school-based oral assessment component into the senior secondary English language curriculum as part of its reform of the high-stakes formal examination system. The aim of this school-based assessment component is to assess authentic oral language use in low-stress conditions using multiple assessment tasks in real time situations (School-Based Assessment Consultancy Team, 2005). One of the characteristics of this school-based assessment is that in contrast to the traditional oral external examination, it shifts control of assessment output to teachers through ensuring that the teachers use a common framework of assessment standards. Consequently, all the teachers involved in this school-based assessment program attend a thorough professional development support program to be trained about the use of the detailed assessment criteria. 
The data for this study were drawn from oral performances by 39 Cantonese-mother-tongue Form 4 (that is, Grade 9) secondary school ESL students engaging in school-based oral English assessment that has recently been implemented across secondary schools in Hong Kong by the Hong Kong Examinations and Assessment Authority (HKEAA). The students, aged 14-17, were all female students. As such, a potential sex-of-interlocutor effect might not represent a variable that would impact on the performance. When this study was carried out, the students were studying in a Band One school $^{1}$ in which the medium of instruction was English except in the Chinese language and history class.

The assessment task which the students engaged in was a group discussion task. This task type is defined by the HKEAA (2010:8) as: an exchange of short turns or dialogue with more than one speaker on a common topic. An interaction is jointly constructed by two or more speakers, hence generally needs less explicit structuring but more attention to turn-taking skills and more planning of how to initiate, maintain and/or control the interaction by making suggestions, asking for clarification, supporting and/or developing each other's views, disagreeing and/or offering alternatives.

Prior to the assessment, students chose their own group members. Each four-member group ${ }^{2}$ was seated in a small circle and given about five minutes for preparation. The topic for each group discussion was to promote a book they had read in the regular reading/viewing program embedded into the English language curriculum, which functions as a springboard to the assessment. Each group discussion lasted about eight minutes. While the participants were engaged in the group discussion, the teacher assessor, who had been well trained through the professional development support program offered by the HKEAA, sat nearby and assessed each participant with a scoring sheet, following the assessment criteria that cover six levels (Level one represents the lowest level and Level six represents the highest level) of oral English proficiency in the four major domains ${ }^{3}$ of English language performance (see Davison, 2007). Each participant thus received a separate score for each of the four domains of assessment criteria, as well as a global score as a result of the aggregation of the domain scores, awarded by the teacher-assessor.

The video-taped group interactions were transcribed following conversation analysis conventions (Atkinson and Heritage, 1984) by a research assistant who was a bilingual speaker of Cantonese and English. The data were then coded by the present researcher himself.

\section{B. Coding the Video-recordings of the Students' Oral Performance}

The coding of the data consisted of four major steps. First, the transcripts of the video-recordings were coded for the following production units (i.e., T-units, clauses, verb phrases and words). The present researcher extracted and put together all that was said by each group member, and then coded each group member's speech for those production units. Secondly, after coding for those production units was done, the subsequent calculation of the frequency of each of those production units, as well as the calculation of the accuracy and complexity measures (see below), was conducted. Thirdly, coding for and calculation of the fluency measures (see below) was conducted. This step of work was carried out separately as it involved viewing the original video-recordings and coding for syllables, pauses, repetitions and reformulations. The whole coding and calculation process was completed by the present researcher by hand in about a month's time. During the coding period, a random sample of four transcripts was checked by another researcher. The discrepancies that arose were then solved by discussion until agreement was reached.

\section{Linguistic (that is, Accuracy, Complexity and Fluency) Measures}

\section{Accuracy}

Following Skehan and Foster (1997, 1999), for this study, accuracy was calculated by dividing the number of error free clauses by the total number of clauses.

\section{Complexity}

Based on a review of complexity-related research work, the following four measures were identified as measures of grammatical complexity used in this study.

1) Length of T-units in terms of number of words

Previous research suggests that T-unit length is capable of discriminating learner interlanguage proficiency satisfactorily (Iwashita, 2006), and has been widely used as a measure of complexity (Skehan and Foster, 1997). "Its relevance is that the more words added to a syntactic structure - while holding it in mind and keeping track of the current clause structure - the heavier the processing load" (Bygate, 1999:196). Both Polio (1997) and Bygate (1999) see a T-unit as a grammatically defined structure, consisting of an independent finite clause plus any finite or nonfinite clauses depending on it. For example,

I think there are so many benefits (one T-unit).

Helen has a horrible date and Peter gets stood up (two T-units).

For this study, the mean length of T-unit was thus derived by dividing the total number of words by the total number of T-units.

2) The number of clauses per T-unit (the T-unit complexity ratio)

\footnotetext{
1 Band One schools represent the best secondary schools in Hong Kong.

2 One group had three group members.

3 These four domains are: Pronunciation \& Delivery; Communication Strategies; Vocabulary \& Language Patterns; and Ideas \& Organization.
} 
Previous L2 studies often report this measure as being indicative of general language complexity. It is assumed that the more clauses per T-unit, the more complex the speech. This measure was calculated by dividing the total number of clauses by the total number of T-units. Following Iwashita (2006), two types of clauses were identified in this study: independent and dependent clauses. For example,

They live together (independent clause) but they are not a couple (independent clause).

They will sing songs (independent clause) when the children get into trouble (dependent clause).

3) The ratio of dependent clauses to the total number of clauses (the dependent clause ratio)

This measure reflects the degree of embedding. It was calculated by dividing the number of dependent clauses by the total number of clauses.

4) The number of verb phrases per T-unit (the verb-phrase ratio)

This measure was calculated by dividing the total number of verb phrases by the total number of T-units. Verb phrases refer to all nonfinite verbs, that is, bare infinitives, to infinitives, gerunds, and gerundives (see Wolfe-Quintero et al., 1998). For example,

He always dreamed of playing in the big league (gerund)

What makes you think this way? (bare infinitive)

3. Fluency

Following Kormos and Dénes (2004), Yuan and Ellis (2003), and Ellis and Yuan (2005), the following four features were identified as the measures of fluency for this study:

1) Speech rate

Speech rate was calculated by dividing the total number of syllables produced in a given speech sample by the amount of time (expressed in seconds) required to produce the speech sample, including pause time. The outcome was then multiplied by sixty to give a figure expressed in syllables per minute.

2) The number of silent pauses per minute

In analyzing pauses, pauses over 0.2 seconds were considered. The total number of pauses was then divided by the total amount of time spent speaking expressed in seconds. The outcome was then multiplied by sixty.

3) The number of filled pauses per minute

The total number of filled pauses such as "uhm", "er", "mm" were divided by the total amount of time expressed in seconds. The outcome was then multiplied by sixty.

4) The number of repetitions and reformulations per minute

The total number of repetitions and reformulations were divided by the total amount of time expressed in seconds. The outcome was then multiplied by sixty.

\section{The Eysenck Personality Questionnaire}

The Eysenck Personality Questionnaire (EPQ) is one of the most widely used psychometric tools in research on personality. This study used the concise version of the EPQ, i.e., the Eysenck Personality Questionnaire-r (EPQ-r) (Eysenck, Eysenck and Barrett, 1985) to determine their degree of extroversion. The extroversion-introversion scale in the EPQ-r has 12 questions that identify the level of extroversion. The higher the score on the 12 items of the extroversion-introversion scale, the more the subject tends towards the extroversion personality trait.

\section{E. In-depth Analysis of Discourse and Interaction of an Extrovert and an Introvert}

To provide further insights into the issue of extroversion-introversion and group oral performance, an in-depth analysis of the nature of discourse and interaction was undertaken of two participants classified as an extrovert and an introvert based on their scores on the 12 items of the extroversion-introversion scale in the Eysenck Personality Questionnaire.

\section{RESULTS}

\section{A. Correlation between Degree of Extroversion and Students' Assessment Scores}

To examine the relation of both the global scores and domain scores awarded to each participant with the level of extroversion, Pearson's correlation was performed. As can be seen in Table 1, both the participants' global scores and domain scores awarded by the certified teacher-assessor appear to show almost no correlation with extroversion level. These findings seem to echo the findings of Ehrman and Oxford's study (1995) that revealed no effect of extroversion on end-of-training linguistic performance measures.

TABLE 1

CORRELATION OF ASSESSMENT SCORES WITH EXTROVERSION LEVEL

\begin{tabular}{lc}
\hline Assessment scores & Extroversion \\
\hline Global score & -.027 \\
Pronunciation and delivery & .092 \\
Communication strategies & -.070 \\
Vocabulary and language patterns & -.052 \\
Ideas and organization & -.077 \\
\hline
\end{tabular}




\section{B. Correlation between Degree of Extroversion and Discourse-based Measures}

To examine the relation of the 9 discourse-based measures with the level of extroversion, Pearson's correlation was also performed. The figures for fluency, accuracy, and complexity measures were correlated with extroversion level measured by the EPQ-r. As is shown in Table 2, three linguistic measures (i.e., error-free clauses ratio, number of clauses per T-unit, and number of silent pauses per minute) obtained small and non-significant correlations with level of extroversion; whereas all the other linguistic measures generated almost no correlations, which are not worth reporting. Overall, the figures in Table 2 thus do not seem to suggest any clear effects of extroversion on individual's oral linguistic performance in this study. Worthy to note is that statistics in Table 2 show that one of the fluency measures, i.e., number of silent pauses per minute, demonstrated a positive correlation with extroversion. This is somewhat in contrast to Dewaele and Furnham's (2000) observation that the more extroverted speakers tended to speak with a faster speech rate and with fewer pauses in their speech.

TABLE 2

CORRELATION OF LINGUISTIC MEASURES WITH EXTROVERSION LEVEL

\begin{tabular}{lc}
\hline Linguistic measures & Extroversion \\
\hline Ratio of error-free clauses to total number of clauses & -.124 \\
Length of T-unit & .001 \\
Number of clauses per T-unit & -.125 \\
Ratio of dependent clauses to total number of clauses & .025 \\
Ratio of verb phrases to total number of T-units & .046 \\
Speech rate & -.052 \\
Number of silent pauses per minute & .169 \\
Number of filled pauses per minute & -.004 \\
Number of repetitions and reformulations per minute & .017 \\
\hline
\end{tabular}

\section{In-depth Analysis of Discourse and Interaction of an Extrovert and an Introvert: Cathy and Shirley}

We now take a detailed look at the oral performance produced by the two participants, Cathy and Shirley. Cathy was classified as an extrovert as her score on the extroversion-introversion scale in the questionnaire was 12, the highest score on the scale, whereas Shirley was classified as an introvert as her score on the extroversion-introversion scale was 1 , the lowest score on the scale. In terms of the four major domains of the task performance assessed by the teacher, both Shirley and Cathy were assigned the same score on Pronunciation and Delivery and Ideas and organization, but Shirley scored higher in Communication Strategies, and Vocabulary and Language Patterns, which enabled Shirley to obtain a remarkably higher global score.

First, within Cathy's group, she gives the impression that she takes the lead in the group by using a better range of turn-taking strategies than most of the group to initiate and maintain interaction, questioning others as well as expressing her own ideas:

Extract 1

1 Cathy: I've read a book Making Friends, which is written by the famous author

2 Andrew Matthews. Did anyone of you read it before?

3 Ivy: I read that before. It mention that human relationship is the source of most of life's pleasure

4 and pain.

5 Betty: It is a book about how to improve the relationship with the people around

$6 \quad$ us and how to make friends with others.

7 Cathy: It tells us some points of how to get along with each other and the way of

8 communication with our friends.

9 Ivy: The point mentioned in the book was filled with examples and cartoons (.2) which make us

10 easy to understand and (1.0) deepen our impression.

11 Cathy: Yes, the comics inside (.2) also attract the readers' attention and the words in the book are not

12 too difficult for us to read and easier to understand.

Extract 1 shows that the discussion begins with Cathy assuming an initiator role to orient the whole group to the assigned assessment task. This orientation is displayed through her saying I've read a book Making Friends, which is written by the famous author Andrew Matthews. Did anyone of you read it before? Immediately, Cathy's opening move is followed by two other members' contributions that substantially topicalize Cathy's s initiation. Following up the contributions, Cathy comments in Line 7: It tells us some points of how to get along with each other and the way of communication with our friends, which leads to further response from a peer group member about the content of the book. In Lines 11-12, Cathy's turn nicely builds on the preceding utterance and provides further comments on the content of the book. It can thus be seen that Cathy apparently assumes the role of interaction manager who initiates question moves, follows up other speakers' contributions in a timely manner, sustaining and extending conversational exchanges in the interaction.

Extract 2 below seems to suggest that Cathy is somewhat a risk-taker, willing to open her mouth and try to 
communicate:

Extract 2

26 Betty: Let us say how to advertise our book because we are going to publish it.

27 Judy: Okay.

28 Cathy: Okay. We should (0.5) umm, umm (.4) ((smile)) what should we do?

29 Betty: Umm I think we should talk about the attractive points of this book and try to think of the

30 ways to advertise it. So I think um the book cover is

$31 \quad(.2)$ very attractive and teenagers will I think teenagers will (.5) will

32 like (.8) this.

33 Cathy: ((looking at Betty and nodding))The cover of the book is very important. Um it should be

$34 \quad$ colourful and (.5) um um more pictures.

In Line 26 of Extract 2, Betty suggests that the group talk about the ways to advertise their book. The next speaker replies with an Okay (Line 27). Cathy's follow-up in Line 28 reflects her efforts to take up Betty's challenging question and figure out concrete ways to advertise their book. Yet, Cathy somewhat got stuck in this as is shown in the following filled and unfilled pauses. With a smile as a springboard to get her out of this dilemma, she immediately asks what should we do to maintain interaction. Cathy's verbal behavior here indicates that she is willing to take up challenging questions, probably she is being a bit adventurous, yet she adapts herself well when she finds herself caught in a dilemma. Meanwhile, Extract 2 reveals that Cathy shows the ability to use some features of appropriate body language to encourage and display interest through smiling, nodding, and making good eye contact not only when listening, but also when speaking.

It can also be seen from the transcript that Cathy actively assists other group members to both find the right linguistic forms and to express meaning:

Extract 3

48 Ivy: It's no fun to be alone so I think (.5) by reading this book can (1.0)

49 Cathy: improve the relationship

In Line 48 of Extract 3, there appears a long pause at the end of Ivy's utterance It's no fun to be alone so I think (.5) by reading this book can (1.0), suggesting Ivy has apparent difficulty choosing appropriate words to say what she wants to say. Seeing this, Cathy interjects with improve the relationship in Line 49 . In this case, Cathy's scaffolding suggesting things Ivy could say - casts her as a sympathetic and supportive peer group member.

In addition, the closing implicative talk is further illustrative of Cathy's role as the 'principal interlocutor' during this group discussion:

Extract 4

136 Betty: You should think in a positive way.

137 Cathy: Yes and learn the good things (.5) in the book. And make friends with

138 each other.

139 Betty: I think this book (.2) is suitable for (.8) people of any age because it

140 teaches us how to (1.0) err deal with (.2) the (.5) problems around us.

141 Ivy: Like bullying others.

142 Betty: Yes. It also teaches us how to handle criticism.

143 Cathy: Yes, so anything else to say?

144 Judy: No.

145 Cathy: Okay. This is the end.

This closing phase of the talk shows how Cathy makes 'arrangements' (see Lines 137 and 145) to smoothly bring the discussion to an end, providing evidence that Cathy plays an essential role in bringing the discussion to completion.

Within Shirley's group, it is discovered that Shirley only has 2 turns throughout

the interaction, one of which is an initiating turn at the beginning of the talk in her group:

Extract 5

1 Shirley: Good morning everyone. Today we are going to discuss about how can

2 we advertise and promote this book Bullying. Um (1.0) it is written by

3

4

5

6

6

8

9

10

11

12

from youngsters who are being bullied and in these emails the teenagers often write about their experiences and feelings of being bullied. And

they were asked about the questions that worry them. And Ann (.2)

Aidan or Ann will reply them by telling them the best solutions and encouraging them to stand up and voice out their problems. This book is an extract of these emails between the authors and (.5) the teenagers.

They pick up the most common problems, which make the teenagers

most anxious. After reading this book we have a better understanding of bullying.

In contrast to Cathy's initiating utterances, this long turn of Shirley's is full of long and complex sentences with 
well-organised structure. Her pace, probably most accurately described as deliberate, shows some hesitation. When speaking, however, her eyes are primarily focused on the camera, and occasionally she is looking down at the sheets of notes in front of her. Regardless of how sophisticated and varied her vocabulary and language patterns are, this initiating move of hers seems to have been scripted in advance and is probably simply read aloud.

The other chunk of speech Shirley makes represents an attempt to initiate a new topic for interaction, but it seemingly ignores the previous remarks. In other words, she seems to initiate the next part of the interaction without making any response to the previous speaker:

\section{Extract 6}

52 Jenny: Yea, culture. And I think that this can make people know better about (1.0) are they

53 bullying others or they are (.2) just (1.0) teasing others.

54 Shirley: I think apart from the book is useful another selling point is it is easy to

55 read. It is because (.5) um it is categorized (.2) into different parts and but topic of each

56 chapter is a question and there are emails regarding to that question but (.5) um it is not in

57 a whole paragraph form like other books to do.

Extract 6 shows that Shirley presents ideas clearly and with well-organised structure. Her language patterns appear complex. Probably because of this, the assessor might get the impression that she probably has a good grasp of vocabulary and language patterns. Her weakness, however, lies in the relevance of her ideas and the appropriateness of her responses to others. In Lines 52-53, the preceding speaker, Jenny, seems to be talking about the linkage between culture and bullying behaviour. In Line 54, instead of making any comments or acknowledgement about Jenny's remarks, Shirley directly starts with "I think apart from the book is useful another selling point is it is easy to read.", which seems not much connected to the content of the Jenny's turn, but quite related to Shirley's own initiating turn in Extract 5. In addition, throughout the interaction, it can be seen from the videotape that Shirley is nearly always focused on her own speech and does not show interest in what others are saying. The awkwardness in the relevance and organisation of her contributions to the interaction may thus lead us to doubt her willingness and ability to respond contingently to others.

\section{DISCUSSION AND CONCLUSIONS}

This study examines the potential impact of learner personality characteristics on their L2 oral performance in a group oral assessment context. The results show no significant correlations between degree of extroversion and students' assessment scores, and between degree of extroversion and those discourse-based measures. One possibility for this lack of significant correlations could be that the students' personality traits under investigation might not be strong enough to compete with other learner characteristics such as language aptitude, target language proficiency level, or information processing strategies. Moreover, the participants in this study were all female students studying in a local Band One school. This relative homogeneity might lower the effects of extroversion on the linguistic performance, and consequently might result in reduction in correlation strength. Another different group of students might have produced different performance. It is thus possible that profound effect of extroversion on oral linguistic performance could be learner (or culture) specific and context dependent. Similar research needs to be carried out using different groups of students participating in group oral tasks. Another possibility for lack of significant correlations between extroversion and the students' performance could be that the students' personality traits might interact with either learner- or task-related variables in oral assessment situations in unpredictable and highly individual ways , preventing generalised linear associations (such as correlations) from reaching overall significance. Future research thus needs to examine how personality traits may interact with various other variables in affecting L2 performance through use of sophisticated statistical procedures. It is also desirable to carry out longitudinal studies to examine whether and to what extent the effect of the extraversion-introversion dimension on L2 production remains stable over time.

Somewhat in contrast to Dewaele and Furnham's (2000) finding that more extroverted students tended to speak more fluently with fewer pauses, one of the four discourse-based fluency measures in this study, that is, number of silent pauses per minute, obtained a positive correlation with level of extroversion, although this correlation is non-significant. One interpretation of this result might be that when engaged in a speaking task, L2 learners need to think not only about what to say but also how to say it due to the imperfectly learned L2 system (Krashen, 1988). In other words, L2 learners face challenges not only from demands of processing the task itself but also from demands of processing an imperfectly known language. Consequently, in the case of secondary school ESL students, such as the participants in this study, those relatively more extroverted students who might speak more in spontaneous conversations might have silent pauses more frequently as a result of their under-developed L2 interlanguage system.

Finally, the in-depth analysis of the discourse and interaction of the two extreme cases, that is., an extrovert and an introvert, seems to echo some generally hypothesized differences between different personality types in oral production and communication in the SLA literature. The extroverted student in this study apparently demonstrated a more active and responsive participation in the assigned assessment task, reflecting a desire to communicate, and a tendency to lead the interactions and to take up challenging questions. The introverted student's mode of participation seemed to be characterized as being reticent, passive and cautious, and lacked a sense of connection with others. However, it appears that these differences in discourse and interaction between the two students were not reflected in the assessment scores 
awarded. It was likely that the teacher assessor in this study might focus more on some areas of learner performance than on some other areas. Consequently, the teacher assessor factor might have helped to blur the effects of the potential personality distinctions between the two students. This raises the issue of the adequacy of teacher assessor training in the current school-based assessment program. In this case, there seems to be a pressing need to conduct research on the extent to which teacher assessors can be trained to effectively take into account aspects of learner performance in group oral assessment context.

\section{REFERENCES}

[1] Atkinson, J.M. and Heritage, J. (1984). Structures of social action: studies in conversation analysis. Cambridge: Cambridge University Press.

[2] Bachman, L.F. and Palmer, A.S. (1996). Language testing in practice. Oxford University Press.

[3] Berry, V. (2004). A Study of the Interaction between Individual Personality Differences and Oral Performance Test Facets. Unpublished doctoral dissertation. King's College, University of London.

[4] Bygate, M. (1999). Quality of language and purpose of task: patterns of learners' language on two oral communication tasks. Language Teaching Research 3, 185-214.

[5] Carrell, P., Prince, M., and Astika, G. (1996). Personality type and language learning in an EFL context, Language Learning 46: 75-99.

[6] Davison, C. (2007). Views from the chalkface: English language school-based assessment in Hong Kong. Language Assessment Quarterly 4: 37-68.

[7] Dewaele, J-M., and Furnham, A. (2000). Personality and speech production: A pilot study of second language learners. Personality and Individual Differences 28: 355 -365.

[8] Dimitrova-Galaczi, E. (2004). Peer-peer interaction in a paired speaking test: the case of the First Certificate in English. Unpublished $\mathrm{PhD}$ dissertation, Teachers College, Columbia University

[9] Dornyei, Z., and Kormos, J. (2000). The role of individual and social variables in task performance. Language Teaching Research 4: 275-300.

[10] Ehrman, M., and Oxford, R. (1995). Cognition plus: Correlates of language learning success. The Modern Language Journal 79: 67-89.

[11] Ehrman, M. (2008). Personality and good language learners. In, ed. Lessons from good language learners. C. Griffiths, 61-72. Cambridge: Cambridge University Press.

[12] Elder, C. and N. Iwashita. (2005). Planning for test performance: Does it make a difference? In, ed. Planning and Task Performance in a Second Language. R. Ellis, 219-38. John Benjamins

[13] Ellis, R. and Yuan, F. (2005). The effects of careful within-task planning on oral and written task performance. In, ed. Planning and Task Performance in a Second Language. R. Ellis, 167-92. John Benjamins.

[14] Hong Kong examination and Assessment Authority. (2010). English Language School-based Assessment Teachers' Handbook.

[15] Esenck, S.B.G., Eysenck, H. J., and Barrett, P. (1985). A revised version of the Psychoticism scale. Personality and Individual Differences 6: 21-29

[16] Eysenck, H. J., \& Eysenck, M. W. (1985). Personality and Individual Differences: A Natural Science Approach. New York: Plenum.

[17] Harrington, M. (1986). The T-unit as a measure of JSL oral proficiency. Descriptive and Applied Linguistics 19: 49-56.

[18] Iwashita, N. (1996). The validity of the paired interview format in oral performance Assessment. Melbourne Papers in Language Testing 8: 51-66.

[19] Iwashita, N. (2006). Syntactic complexity measures and their relation to oral proficiency in Japanese as a foreign language. Language Assessment Quarterly 3:151-169.

[20] Kormos, J., and Dénes, M. (2004). Exploring measures and perceptions of fluency in the speech of second language learners. System 32, 145-164.

[21] Krashen, S. (1988). Second Language Acquisition and Second Language Learning. Prentice-Hall International.

[22] Mislevy, R.J., Steinberg, L.S., and Almond, R.G. (2002). Design and analysis in task-based language assessment. Language Testing 19: 477-496.

[23] Naiman, N., Frohlich, M., Stern, H. H., and Todesco, A. (1978). The good language learner. Toronto: Ontario Institute for Studies in Education.

[24] Nakatsuhara, F. (2006). The impact of proficiency-level on conversational styles in paired speaking tests. Research notes 25.

[25] Ockey, G. (2009). The effects of group members' personalities on a test taker's L2 group oral discussion test scores. Language Testing, 26, 161-186.

[26] O'Sullivan, B. (2002). Learner acquaintanceship and oral proficiency test pair-task performance. Language Testing 19: $277-95$.

[27] Polio, C. (1997). Measures of linguistic accuracy in second language writing research. Language Learning 47: $101-143$.

[28] Robinson, P. (1995). Task complexity and second language narrative discourse. Language Learning 45: 99-140.

[29] Skehan, P. and Foster, P. (1997). Task type and task processing conditions as influences on foreign language performance. Language Teaching Research 1: 185-211.

[30] Skehan, P., \& Foster, P. (1999). The influence of task structure and processing conditions on narrative retelling. Language Learning 49: 93-120.

[31] School-Based Assessment Consultancy Team. (2005). 2007 HKCEE English examination: Introduction to the school-based assessment component. Hong Kong: HKEAA.

[32] Spence-Brown, R. (2001). The eye of the beholder: Authenticity in an embedded assessment task. Language Testing 18: 463-481.

[33] Swain, M. (1993). The output hypothesis: Just speaking and writing aren't enough. The Canadian Modern Language Review 50: 158-164. 
[34] Swain, M. (2001). Examining dialogue: Another approach to content specification and to validating inferences drawn from test scores, Language Testing 18/: 275-302.

[35] Wolfe-Quintero, Kate, Shunji Inagaki and Hae-Young Kim (1998). Second Language Development in Writing: Measures of Fluency, Accuracy and Complexity. Honolulu: University of Hawai'i Press.

[36] Yuan, F. and Ellis, R. (2003). The effects of pre-task and on-line planning on fluency, complexity and accuracy in L2 monologic oral production. Applied Linguistics 24: 1-27.

Zhengdong Gan is currently an Assistant Professor in the Department of English at the Hong Kong Institute of Education. He obtained his PhD in applied linguistics from the Hong Kong Polytechnic University in 2003. His research interests include second language performance assessment, conversation analysis, and self-directed language learning. He has published in Applied Linguistics, International Journal of Applied Linguistics, Australian Review of Applied Linguistics, and Language Testing. 